Portland State University

PDXScholar

\title{
Environmental Justice and GIS: A Comparison of Three GIS Methods for Estimating Vulnerable Population Exposed to Brownfield Pollution in Portland, Oregon
}

Kyle Goodman

Portland State University

Follow this and additional works at: https://pdxscholar.library.pdx.edu/geog_masterpapers

Part of the Geographic Information Sciences Commons, and the Physical and Environmental Geography Commons Let us know how access to this document benefits you.

\section{Recommended Citation}

Goodman, Kyle, "Environmental Justice and GIS: A Comparison of Three GIS Methods for Estimating Vulnerable Population Exposed to Brownfield Pollution in Portland, Oregon" (2017). Geography Masters Research Papers. 19.

https://pdxscholar.library.pdx.edu/geog_masterpapers/19

10.15760/geogmaster.19

This Paper is brought to you for free and open access. It has been accepted for inclusion in Geography Masters Research Papers by an authorized administrator of PDXScholar. Please contact us if we can make this document more accessible: pdxscholar@pdx.edu. 


\title{
Environmental Justice and GIS: A Comparison of Three GIS Methods for Estimating Vulnerable Population Exposed to Brownfield Pollution in Portland, Oregon.
}

By

Kyle Goodman

\begin{abstract}
A Research Paper Presented for Partial Fulfillment Of Master of Science Degree in Geography

At the College of Liberal Arts and Sciences

Office of Graduate Studies

Portland State University
\end{abstract}

May 2017 


\section{Table of Contents}

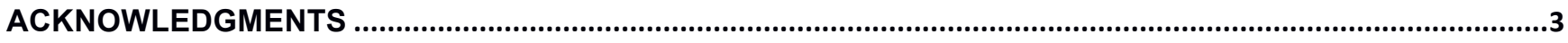

LIST OF FIGURES

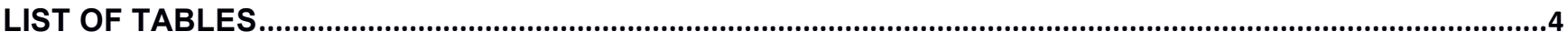

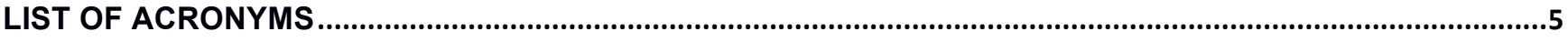

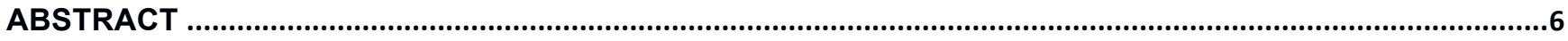

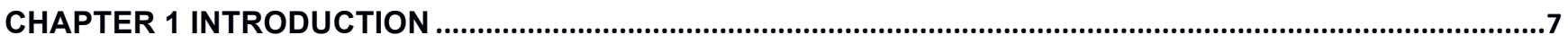

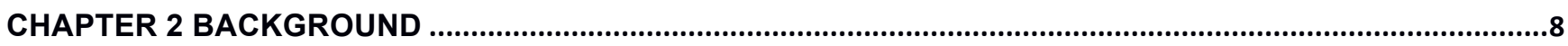

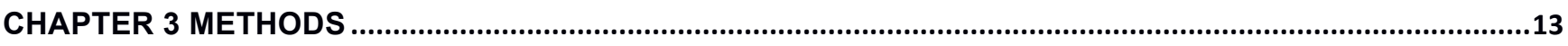

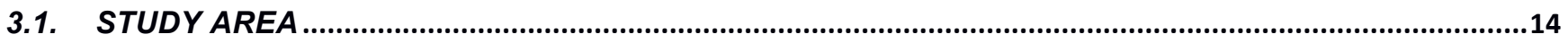

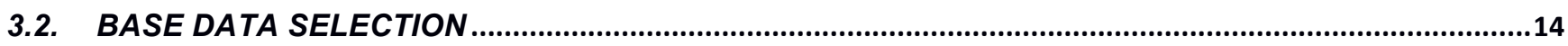

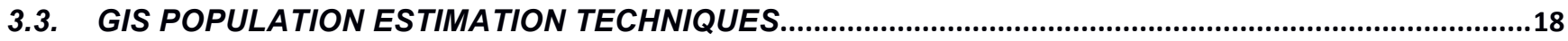

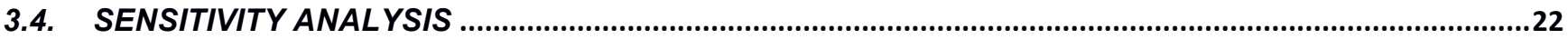

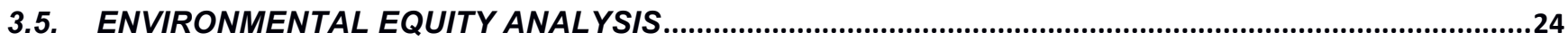

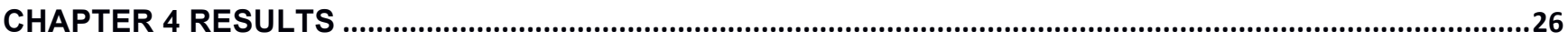

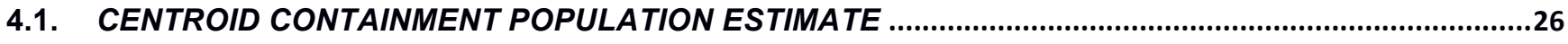

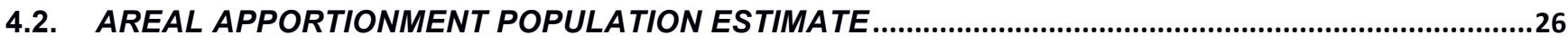

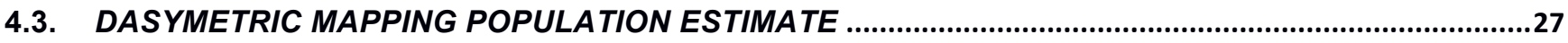

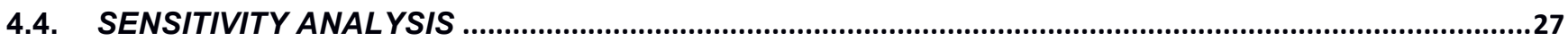

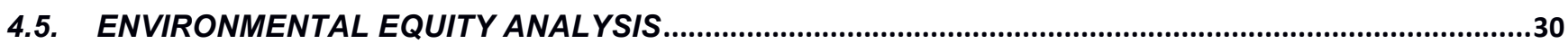

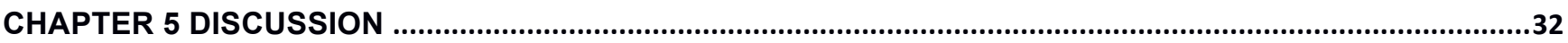

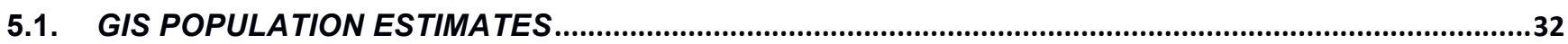

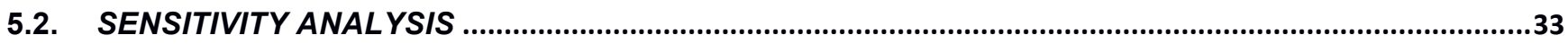

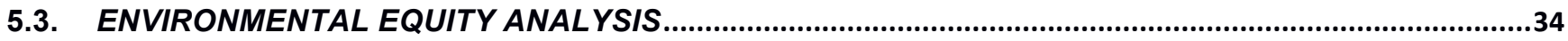

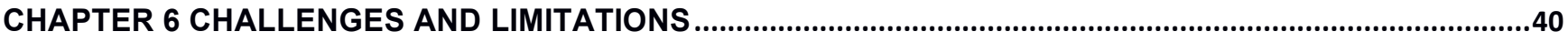

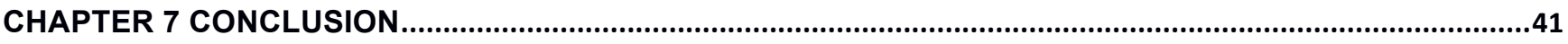

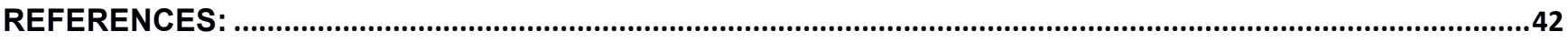




\section{ACKNOWLEDGMENTS}

I would first like to thank my thesis advisor Dr. Jiunn-Der (Geoffrey) Duh of the Department of Geography at Portland State University. Professor Duh's office was always open whenever I had a question about my research or writing. He consistently allowed this paper to be my own work, but regularly pointed me in the right direction whenever he thought I needed it.

I would also like to thank the committee members who were involved in the validation of this research project: Dr. Martin Swobodzinski and Mr. Brian Harper. Without their willingness to participation and input, the validation for this research could not be successfully conducted.

Lastly, I would like to thank my wife, daughter, and son for their graciousness and willingness to allow me the freedom and time to work on this research.

Thank you. 


\section{List of Figures}

Figure 1: Study Area Map

Figure 2: GIS Estimate Methods

Figure 3: Correlation Coefficient - Trend Line Graph for Centroid Containment to Dasymetric Mapping

Figure 4: Bland-Altman Statistical Agreement Chart

Figure 5: Map of Site 29

Figure 6: Map of Site 32

Figure 7: Map of site 3

Figure 8: Map of Site 19

\section{List of Tables}

Table 1: Correlation Coefficients R-Values for All Distance Intervals

Table 2: Environmental Equity Analysis Results for All Three Methods

Table 3: Environmental Equity Analysis Results Key Statistics 


\section{List of Acronyms}

CERCLA - Comprehensive Response, Compensation, and Liability Act DEQ - Department of Environmental Quality

ECSI - Environmental Contamination Site Information

EPA - Environmental Protection Agency

GIS - Geographic Information Systems

LIDAR - Light Detection and Ranging

MAUP - Modifiable Areal Unit Problem

MFR - Multi-Family Residential

Metro - Oregon Metropolitan Planning Organization

PPB - People per Building

RLIS - Regional Land Information System

SFR - Single Family Residential 


\begin{abstract}
This project compares three GIS techniques that estimate populations who are potentially affected by environmental contamination in Portland, Oregon. All three GIS techniques utilize polygon containment to estimate populations potentially exposed to pollutants based on block level census data. In this study, multiple buffer distances at half-mile increments were used across all three techniques. Circular Euclidean distance buffers surrounding a known contaminated property, such as documented brownfields, approximate the contamination zone. Accurate estimates for populations exposed to harmful environmental conditions could provide a better understanding of environmental justice issues. The specific research questions were: 1) Are the population estimates sensitive to the GIS techniques used? 2) Are higher proportions of minority populations closer to brownfields than the general population? The three population estimation techniques are: the centroid containment method, areal apportionment method, and vector-based dasymetric mapping. Centroid containment method assigns the population of a census enumeration unit to its centroid. If the centroid falls within the contamination zone, then the total population of the census unit is counted as being exposed to the pollutant. Areal apportionment method estimates exposed populations by calculating the population based on its proportional size for the area of the census enumeration unit that falls within the contamination zone. Vector-based dasymetric mapping redistributes the population into areas that correspond more directly to resident populations within a census enumeration unit. Building volumes are used to dis-aggregate the census enumeration blocks into smaller spatial units that account for three-dimensional space and more realistically resemble the populations who may reside in the exposure zones. Using the population estimates derived from these methods, I examined if minority populations were disproportionately distributed near brownfields. For question 1, I compared the population estimates from the three methods at various buffer distances to ascertain the reliability of each of their calculations. After the sensitivity analysis was performed, I used a half-mile radius around brownfields as the potential risk area and compared the percentage of minorities in the risk area to the percentage of the total population in the risk area for each of the three GIS techniques. The results indicate all three techniques produced comparable population estimates across the various distance intervals. Consequently, this allowed for a fair comparison across all three GIS methods. In terms of environmental justice the results reported all three estimation techniques to have similar results. As the techniques got more advance, the results showed less inequality for minorities; however, the margin for this difference was only one to two sites depending on which methods are being compared. Also, the vector-based dasymetric method presented a lower percentage of minorities in the risk area when compared to the other two methods, because dasymetric mapping is designed to estimate were people are more likely concentrated. The research from this project presented how GIS could be used to investigate environmental justice, and how different spatial analysis methods could result in uncertainty with population distribution.
\end{abstract}




\section{Chapter 1 Introduction}

As urbanization continues to speed up worldwide and the urban core in American cities has major revitalization efforts, the need to understand the social inequality within these communities is a frequently sought piece of information. Since the industrial revolution, environmental pollution and its effects on society are widely researched topics (Bowen and Wells 2002). Environmental justice is a social movement centered on the fair distribution of environmental burdens and benefits (Sheppard et al. 1999). Environmental justice is a mechanism used for measuring the social justice within communities by social scientist, like urban planners, geographers, sociologists, and economists. Identifying which groups are most affected by contamination and where they are located are two key components to understanding environmental justice issues. The most common groups to be examined are minority populations.

Geographic information systems (GIS) are an important tool for analyzing and visualizing spatial and demographic data. Over the past two and a half decades GIS has been used to support decision making for environmental justice policy and it is used to measure environmental equity. Proximity to environmental contamination is a common way GIS is used for measuring the risk associated with environmental burden. The parameters for measuring how much risk a contaminated site creates and the parameters for defining who may be affected are often disputed amongst the different disciplines that study environmental justice. This is due to the reliability of data or improperly estimating who and where people are affected. Environmental justice is heavily reliant on reporting and analysis from within the community and governing agencies, not from the polluters themselves (Mah 2017). It is imperative to properly estimate populations when measuring equity. 
The purpose of this study is to compare three GIS approaches for population estimates used in proximity analyses. Accurate estimates for populations most burdened by risks associated with environmental contaminates are useful for agencies trying to reuse or revitalize land within blighted neighborhoods. It allows for a spatially targeted approach to address the burdens being placed on environmentally disadvantaged social groups. The goal is to observe which estimation method has the greatest effect on the results for measuring environmental inequities. Specifically, the research questions are: 1) Are the population estimates sensitive to the GIS techniques used? 2) Are higher proportions of minority populations closer to environmental contaminates than the general population?

\section{Chapter 2 Background}

Land use within urban areas tend to change more frequently than those of rural areas, at least in terms of human interaction over time (Lambin et al. 2001); this is not to say that the development of previously natural areas is less controversial, but due to population density urban areas are more likely to have an effect on larger portions of the population (Schadler et al. 2010). Urban environments generate higher concentrations of industrial and commercial property, which can contain pollutants. These property types are often adjacent to residential properties. In urban regions a wide spectrum of properties with pollutants are created. Generally, the overall scale of contamination drives attention the public and public agencies focus on issues of environmental contamination.

Large-scale contamination sites, like Love Canal or the Hanford Nuclear facility tend to garner the most political and public consideration (Arvai and Gregory 2003). These sites earn their reputations because they affect large populations and huge swaths of natural environment. Love Canal affected the people living directly on top of the contaminates site, and the Hanford Nuclear Facility affects people living nearby as well as downstream along the 
Columbia River. The Hanford site is a 585 square-mile portion of land located in the southeastern portion of Washington State, and it effects many towns and cities along the Columbia River. The Hanford site, a government funded nuclear testing facility from World War 2, was a part of the Manhattan Project (US EPA website). A significant environmental cost of researching nuclear weapons is the creation and disposal of nuclear waste. At Hanford much of the waste is stored in barrels and buried. This resulted in the nuclear waste leaching into the soil and ground water.

Love Canal in upstate New York illustrates the immediate consequences of living on or near environmental contaminates. Love Canal was the result of developing a neighborhood for the City of Niagara Falls directly on top of a known hazardous waste dumpsite. Multiple companies dumped chemical waste used in the production of electronics and batteries into the then unfinished canal. Not long after the dumping of chemicals halted, the city of Niagara Falls purchased the land to develop a new school district and neighborhood. The results of which led to a community of people having abnormally high white blood cell counts which is a precursor to leukemia, and chromosomal damages which caused a high number of miscarriages, retardation, and cleft facial features. It was determined that the pollutants on which they were living caused the poor health condition of this community.

Love Canal is widely recognized as an important case for environmental justice issues in the US because it helped reform environmental policies at the federal level. Complexities of determining responsible parties forced the litigation before the US Supreme Court. The case resulted in the evacuation of the homes at Love Canal, and the relocation of 800 families. It is the reason why the US created the Comprehensive Environmental Response, Compensation, and Liability Act of 1980 (CERCLA). Love Canal proved a public health threat and proved there were parties liable in legal terms (Holifield 2012). 
CERCLA highlights a few key components in regards to the remediation of site contamination large and small. First, it helps identify areas where contamination exists by giving comparable figures. Second, it helps determine the responsible and liable party through historical business and land ownership research. Third, and most importantly, it has set standards for reporting and controlling hazardous material for operating companies, which influenced new laws and regulations for agencies currently operating with hazardous material.

Larger sites like Hanford and Love Canal are now classified as superfund sites. A superfund site status granted by the US Environmental Protection Agency (EPA) as a location with enough contamination to pose risk to human health and sanction federal funding for cleanup (Elliot and Frickel 2011). While these typologies deserve the attention they gain and while they act as strong examples for characterizing issues of environmental contamination and environmental equity, it led to smaller instances being overshadowed by the larger examples.

Smaller sites are classified as brownfields and tend to be found in urban areas. A brownfield is defined as an "abandoned, idled, or under used industrial and commercial facilities where expansion or redevelopment is complicated by real or perceived environmental contamination" (De Sousa 2003). A brownfield can be anything from a former gas station or dry cleaner to an abandoned industrial or commercial manufacturing plant. In fact many argue that the accumulated effects from multiple smaller sites pose higher levels of risk for the populations that surround them (Thomas 2002). In some cases there are locations that contain many smaller sites with enough overall contamination to be considered a superfund site.

Research continues to reveal that such brownfield sites constitute a national, if not global, problem (Dillon 2014). In urban environments one of many factors leading to a decline 
in health is proximity to contamination. It's important to note that the research prior to 2002 often suggested that urban areas have biased results because the scope is too small and urban areas are known to be more poor and racial diverse. However, this is changing as recent development and planning efforts are revitalizing the urban core. The reporting of brownfields has increased with the revitalization efforts. Many land uses became hidden over time due to lackadaisical reporting, and are now being revealed as potential sources of pollutants.

A key driver for the increase in urban revitalization is urban growth boundaries. The implementations of urban growth boundaries are the result of people wanting to cordon off the urban areas from rural and natural landscapes (Harvey and Works 2002). The prevalence of redeveloping brownfields increased significantly throughout the past decade. In part, this is due to the rise of sustainable development. Sustainable development is defined as "development that meets the needs of the present without compromising the ability of future generations to meet their own needs." (World Commission on Environment and Development 1987). Sustainability frames brownfield redevelopment as a land use strategy for recycling land. The larger urban areas are recognizing vacant and underutilized lands as an untapped resource for increasing tax revenue, reducing sprawl, and absorbing population growth (Thomas 2002). It is often the case that these lands have been left vacant and underutilized for a reason; presumably it is due to environmental pollutants.

Cleanup and restoration is a risk management mechanism. It is triggered once a hazard has been identified. Scientists define the total risk evaluated from site by measuring the area of contamination, the potential exposure level, and the potency of the hazardous material. Such evaluations inform decision makers on methods, costs, and time frame for the remediation process. The remediation process rarely seeks to completely clean a site since 
there will always be some form of risk; rather, remediation aims to reduce risk to an acceptable level. Therefore, the question is, what is an acceptable level of risk? (Masters 2008). The acceptable level of risk is based on the type or types of pollutants, which can vary greatly from site to site. Also, testing soil, air, and water quality can be expensive and time consuming. Regardless, cleanup and restoration is a necessary process for protecting social, economic, and environmental health.

Assessing which populations are affected by environmental contamination is contingent upon two geographic aspects. The first is the size, shape, or area of contamination. This refers to the extent at which a pollutant has enough toxicity to harm the population. The delineation for the area of effect depends upon the type of contaminates and the abundance where contaminates are measured. The second geographic aspect is the population characteristics for those impacted by potential exposure. Demographic data and its delineation determine who the impacted populations are (Chakraborty et al. 2011; Sheppard et al. 1999; Sridharan and Qiu 2013). The characteristics of the impacted populations are defined by surveys; the most notable being the United States Census. The US Census is a decennial population and housing count for determining the population dynamics of citizens residing within the country. The US Census primarily looks at resident populations, which is also known as nighttime population.

A nighttime population refers to a place of residence where people tend to spend their evenings and nights. A distinction between daytime and nighttime population is important because people may be living in a setting more susceptible to exposure without knowing it. Daytime population refers to people's daily habits where they leave their house for an activity, such as work or school. Generally, length of exposure is the leading metric for increasing risk of illness due to carcinogens and other chemicals. Therefore, if people spend the majority of 
their time at their residence, then they are at a higher risk for exposure when environmental contaminates are near. More accurately estimating where nighttime populations are most prevalent will provide information on burdened communities at risk, and hopefully assist policy makers to relieve these environmentally burdened communities.

Spatial science is an inherent part of environmental equity because it relies on measurements of distance to determine who is affected by potentially harmful contamination (Mennis 2002). Demographic information is used to assess the population characteristics near known contaminates. Census data enumerations and their spatial proximity to hazards are used to identify vulnerable populations at risk of exposure to environmental contaminates (Sheppard et al. 1999). GIS can layer population data with contamination sites and the extent of their pollution to elucidate who is affected. GIS can also spatially redistribute demographic information to more closely model the real world. The advantage with GIS is its ability to utilize a variety of data sets that represent information about the real world; however, the quality of the underlying data becomes significant because the analysis can only be as good as its data.

\section{Chapter 3 Methods}

Three different Geographic Information System (GIS) methods for estimating populations are used to measure risk associated with potential exposure to environmental burdens. Initially, a sensitivity analysis determined the comparability between these three techniques. The sensitivity analysis compares the results of all three estimates by plotting the results for one method against the results of another at each interval of distance. It compares the correlation coefficient and an agreement plot from all three techniques to determine if each estimate reliably redistributes the census block populations into new spatial units. After the sensitivity analysis determined the reliability for each GIS technique, an environmental 
equity analysis is produced. The purpose of this analysis is to determine whether higher proportions of minorities are at an increased risk of living in proximity to brownfields.

All three population estimate methods are applied to a proximity analysis known as buffer containment. Buffer containment simply means that any portion of the population that falls within the affected area are counted as exposed. The goal here is to capture the number of residence within buffered distances from the potential contamination source. Each population estimation has its drawbacks and advantages, which will be defined specifically below. Also, both the sensitivity and the environmental equity methodologies are discussed, but first the study area, data collection, and the site selection are described.

\subsection{Study Area}

The study area chosen is the city limits of Portland. It is chosen based on three main factors. First, Portland and its greater metropolitan area have an abundance in GIS data and resources. Second, Portland has a long history of development, which is conducive to the existence of brownfields. Third, the city limits act as an administrative boundary that is used to allocate funds based on population size and characteristics. These three factors contributed to the decision for using the Portland city limits as the main focus area for this project (See Figure 1: Study Area Map).

\subsection{Base Data Selection}

For this exercise the data for all methods are acquired from two governing agencies, the State of Oregon and the Oregon Metropolitan Planning Organization (Metro). The US Census data and Environmental Cleanup Site Information data are prepackaged data sets from the State of Oregon. I chose to retrieve the US Census data from Oregon's database rather than directly from the US Census, because it provided me with the demographic information I needed for my study area without having to compile the data using the Census' 
convoluted database system. The Environmental Site Cleanup Information is data collected by the state of Oregon's Department of Environmental Quality, and it provides a source for the contamination zones representing environmental burden. The third data set is the city boundary, which was collected from Oregon Metro; Metro has a regional database for GIS

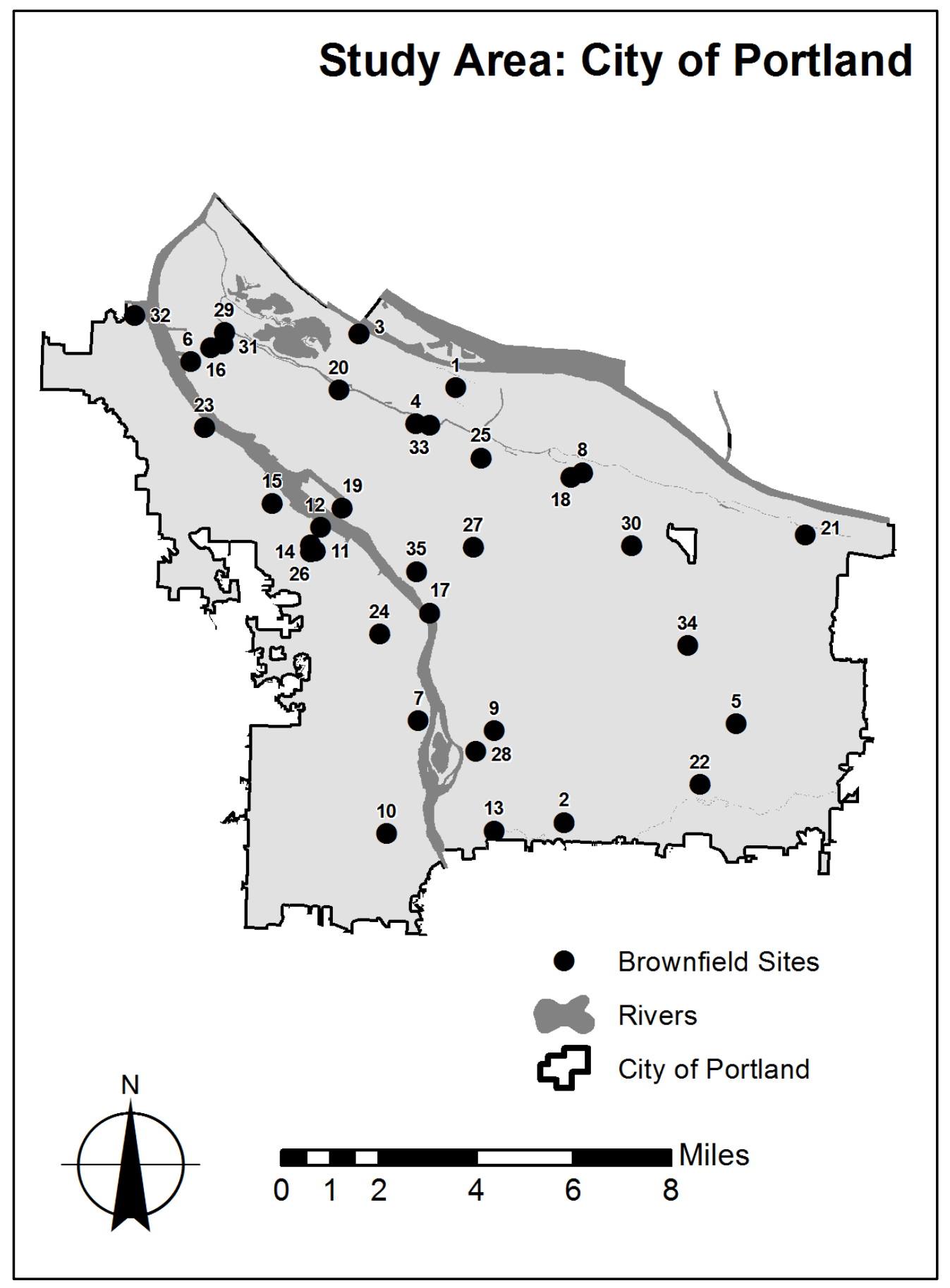

Figure 1: Study Area Map 
data collected from 25 cities and three counties around Portland. Lastly, the fourth data, also provided by Metro, is the buildings GIS data. Buildings data is used as an ancillary spatial unit in the dasymetric mapping population estimate. Each data set will be discussed further and their roles are defined for each method in the subsequent paragraphs.

The first data set collected was the ECSI location data from the Oregon Department of Environmental Quality (DEQ). It was chosen because it contains a list of addresses with suspected, known, and cleaned sites that do or did contain environmental contamination across Oregon; it will act as the source for potential contamination. Preparation of the data begins with site selection. After downloading the ECSI data from Oregon DEQ, it was geocoded based on addresses provided in the data using the Regional land Information System (RLIS) address locator created by Oregon Metro. The RLIS geolocator uses the street networks maintained by Metro to find the locations in the address fields of the ECSI data table.

The next step was to select sites by location to separate out only sites within the Portland city limits. The subsequent step was a query to find sites identified as "listed". Listed means the sites are considered by DEQ as high priority and are confirmed brownfield sites (Oregon DEQ 2016); this means that these sites have some known type of environmental pollutant. In total 35 sites were selected across Portland. The affected areas are created from this data. They are made by buffering a Euclidean circle at five intervals. Those Intervals are: $0.5,1,1.5,2$, and 2.5 miles. The circular straight-line buffers are chosen due to ease of calculation, and their distances are chosen arbitrarily (Zandbergen and Chakraborty 2006; Ghanbari and Ghanbari (2013). This is a limitation of these types of studies, but they act a generic spatial measurement until extents can be better defined. A well-defined extent isn't usually sought until a specific site is under remediation. 
The Second data set is the 2010 US Census blocks downloaded from the state of Oregon's Geospatial Clearinghouse. It was selected because it includes the necessary population attributes from the 2010 Census, and they are mostly uniform and contiguous spatial representations of population (Chakraborty et al. 2011). The population groups used in this study are: total population, American Indian/Native Alaskan, Asian, Black, Hispanic, Native Hawaii/Pacific Islander, White, People who identify as two or more races, and people who identify as some other race not listed. This data set has the Census block polygons for the entire State of Oregon, and it contains the demographic information needed to determine environmental equity. A query for Clackamas, Multnomah, and Washington counties is used to separate out the populations of those counties from the rest of the state. It was the only filter to occur on this data prior to its use within each of the population estimation techniques. This was done to reduce load speeds within the GIS software, and these three counties were selected because the city limits of Portland reach into all three of these counties.

The third and simplest data set used is the boundary polygon data for Portland's city limit. This data is used because it is considered the study area for this research. It was not manipulated in any way and acts solely as an administrative boundary. All data will be constrained to stay within this boundary. Neither demographic data from the census nor any buffered distance from the ECSI sites will reach beyond the city limits.

The fourth data set is for the dasymetric mapping portion. Oregon Metro's building data was used from their RLIS database. It acts as an ancillary spatial unit for the census population within the dasymetric population estimate. Since nighttime populations are the primary concern of this study, then only single-family residential (SFR) and multifamily residential (MFR) buildings were selected. Also, any known detached garages or greenhouses were removed along with the commercial and industrial buildings. Many of the 
buildings had coincident polygons, because they are multiple stories with different polygons representing each story. The volumes attribute in the data was generated by the city of Portland. The metadata states that volumes were derived from the buildings square footage multiplied by the buildings average height. The square footage is found based on the buildings permit information, and the average height was obtained from the light detection and ranging (LIDAR) data used to make the buildings polygons. They are dissolved based on their unique identifier and their volumes are summarized to retain their spatial integrity. This retained the volume for each of buildings parts in one singular polygon and makes sure each control unit across the data set is analogous.

\subsection{GIS Population Estimation Techniques}

The first technique for estimating the population within the contamination zones is the centroid containment method. This technique is the most simplistic because it converts the census enumeration polygons into points within the center of the census block polygon (See Figure 2: Centroid Containment). The demographic information of those polygons is now attributed to the centroid points. The points are then counted when they fall within the Euclidean buffer distances from the brownfield sites. The downside to this method is it still estimates the population as a form of spatial coincidence, because it is counting the entire population of a census block whose centroid falls within the exposed area buffers. By using the centroid not all of census block polygons within the buffers are being counted like they would with spatial coincidence methods. 


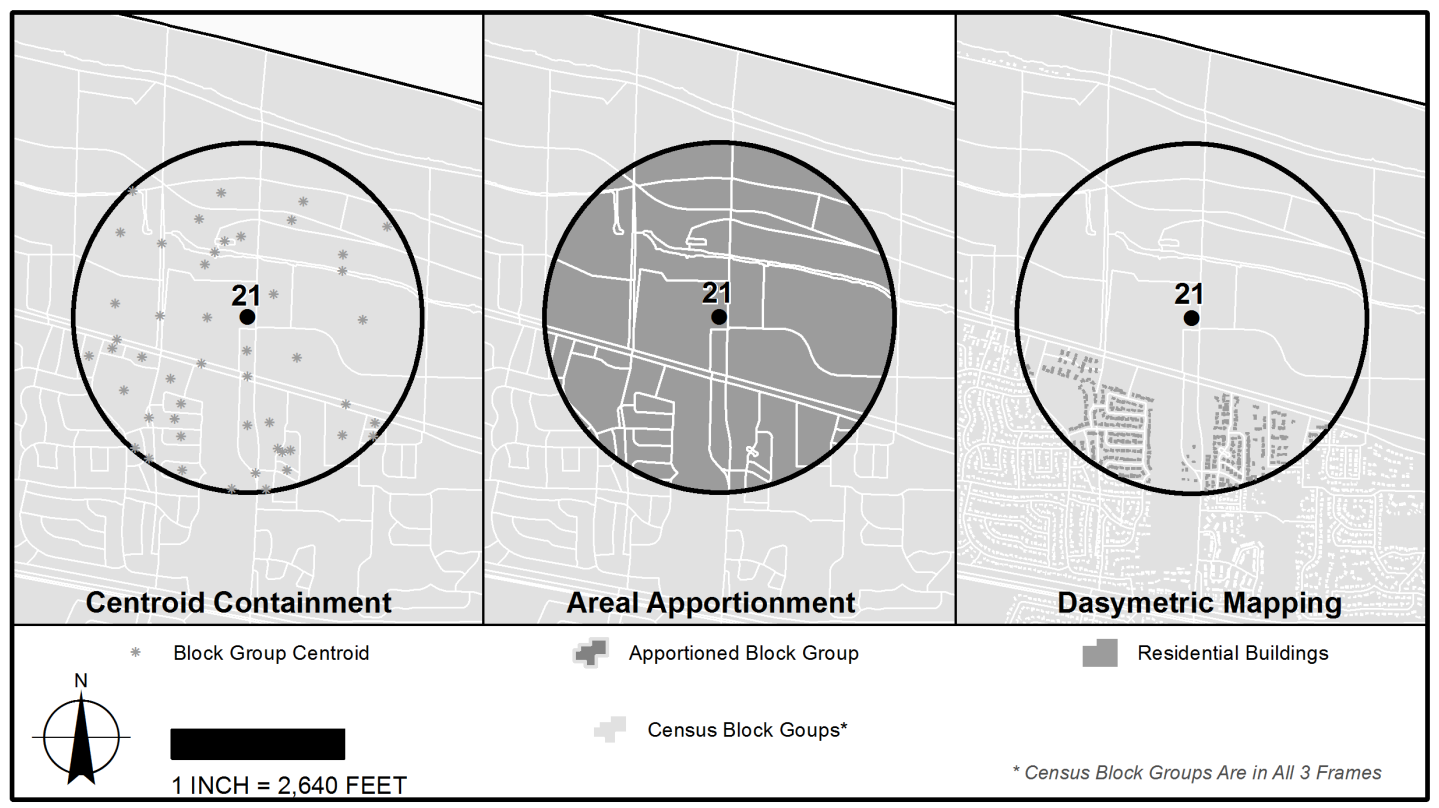

Figure 2: GIS Estimate Methods

The second technique is the areal apportionment method (See Figure 2: Areal Apportionment). The reason this technique was chosen is because it is one of the most commonly used GIS method for population estimating in environmental justice studies (Maantay et al. 2008). This method is heavily reliant on proportional calculations because it recalculates the population based on the percentage of the census block area within the buffered exposure zone. The goal is to include only the population that exists within exposure area and exclude those who are not in it. Areal apportionment selects all census blocks and the fractions of census blocks that are within the buffer distances from the brownfield sites. For the instances where census blocks become divided by the radii of the Euclidean buffers, a simple apportionment weighting occurs. For example, if 15 percent of a census block falls within the buffered area, then only 15 percent of the total population within that census block is counted as being in the affected area. The reason for choosing this method is because it allows for the buffered distance to share the same spatial area as the other methods. In other methods, such as spatial coincidence, each affected area becomes represented by the shape 
of the accumulation of all the census block polygons touching in the affected area. The area will become larger than the actual contamination zone. Spatial uniformity is lost when comparing site to site, because their effected areas change to the shape of their collection of census blocks.

The GIS procedure for estimating the population using the areal apportionment method is to run an intersect geoprocess to find all census blocks and portions of census blocks within the buffered distances of the brownfield sites. The percentages for each census block within the buffered contaminate zones were found by creating a new data field and calculating the new areas of intersected census blocks. The new polygon areas are divided by the old polygon areas to determine the percentage of land within the contamination buffers. The populations within the new census block areas are calculated by multiplying the Population type $(\mathrm{Pt})$, with the percentage of census block area $(\mathrm{Pcb})$ to get the number of people potential affected by contamination (Ps):

$$
P s=P t * P c b
$$

Initially this was computed for total population, and then the process was repeated for each of the seven ethnic sub categories recognized by the US Census. These values are then counted when they fall within the Euclidean buffered distances.

The third method for estimating populations is vector-based dasymetric mapping (see Figure 2: Dasymetric Mapping). The goal for this form of areal interpolation is to estimate people per building within the buffered zones from the brownfield sites. The fundamental argument for using this method is to estimate the population in a more realistic spatial unit rather than using generic shapes that do not have any real world application. Dasymetric mapping is trying to resolve the Modifiable Areal Unit Problem (MAUP). MAUP is a misrepresentation of statistical data through the aggregation of point-based data into larger 
zonal area features (Zandbergen and Chakraborty 2006). In demographic data the people are represented as stationary points, hence the need to examine nighttime population. Dasymetric mapping reorganizes the aggregated data by taking it out of arbitrary geographic boundaries (source units) and redistributes it into a more realistic representation of the data (control units) that can then be measured within the affected area (target units).

In this study the census blocks are the source unit, which assumes that the populations within the blocks live in the middle of street intersections or in parks where we can reasonably know this is not the case. The population data will be redistributed into buildings as the control unit because buildings not only accurately depict nighttime populations, but they also represent vertical space. Vertical space is accounted for in volume and measures population density within multifamily residential buildings, such high-rise condos or apartment complexes. Most common forms of dasymetric mapping use a raster based land use grid as the control units, but this lacks vertical distributions of populations especially in urban areas where we know density increase vertically. A lack of vertical distribution leads to over estimation in urban areas with low-rise buildings, and under estimation in urban areas with high-rise buildings (Sridharan and Qiu 2013). Since the census is restricted from sharing and collecting address specific data or individual level data for reasons of privacy, dasymetric mapping can alleviate this by redistributing the population into a finer spatial resolution. A more detailed resolution allows for a better correspondence between the people being surveyed in the census and the people being counted in the model (Chakraborty et al. 2011).

As mentioned in the data preparation section, all building types that were not multifamily residential or single family residential were removed. In order to calculate people per building (PPB) a spatial join was used on the buildings with the census blocks; knowing how much livable building volume exists in each census block will determine the ratio of 
distribution for the aggregated population estimates. PPB is calculated by dividing the 2010 population type $(\mathrm{Pt})$ by the total building volume $(\mathrm{Bt})$, and multiplying that figure by each individual buildings volume (Bv):

$$
P P B=\left(\frac{P t}{B t}\right) * B v
$$

After calculating for the total population in 2010, a calculation was conducted for each of the seven ethnic segments of the census data to make one value for the entire minority group. These values are then counted when they fall within the Euclidean buffered distances. In order to verify if the vector based dasymetric mapping method is a sufficient measurement of nighttime populations, the populations summarized within the buildings need to correspond directly to the population in the census blocks.

\subsection{Sensitivity Analysis}

For the sensitivity analysis five Euclidean buffers at half-mile increments were used to count populations. The intention is to test if distance has an effect on the three GIS population estimates. A distance based buffer analysis calculates the amount and type of population within the affected area. This is known as spatial containment (Mohai, P 2006). In order to create the contamination zones Euclidean circular buffers are constructed. For the sensitivity analysis a multi-ring buffer is created from the site location. Here, multi-ring buffer refers to the five incremented half-mile Euclidean circular buffers. The sensitivity analysis will illustrate if each population technique measures a change in its estimation pattern, as the distances get larger. If a change occurs, then it may mean the methods are not suitable for comparison.

The observance of change in population estimation is measured through two methods. The first method is the correlation coefficient, and the second method is a Bland-Altman statistical agreement plot. The correlation coefficient is compared between all three GIS population estimate methods in sets of two, and these sets are individually analyzed across 
all five buffer distances. In total 15 comparisons were made. The centroid containment to areal apportionment is compared at all five distance intervals. The centroid containment to dasymetric mapping methods is compared at all five intervals. Lastly, the areal apportionment to dasymetric mapping techniques are compared at all five distances.

The correlation coefficient measures the statistical dependence of the results from the population estimate method to verify if the estimations are similar or dissimilar. Correlation expresses if two variables share a linear relationship or not. Positive correlation must occur to allow for a fair comparison. Correlation coefficients are expressed through their r-values, which have a range between negative one and one. This measures the strength of dependency from the results of one method to the results from the other methods. Positive correlation means that the population's estimates are sharing approximately the same trend in their results. The correlation for each GIS population estimate is compared by creating a Cartesian scatter plot where the results from one estimate is placed on the $\mathrm{x}$-axis and the result from another estimate is placed on the $y$-axis.

The Bland-Altman agreement plot is also compared between all three GIS techniques across all five distance intervals. The Bland-Altman plot is used to find statistical agreement between two differing methods that are designed to measure the same property (Bland and Altman 1983). Statistical agreement measures how much one method differs from the other. This is different from correlation because correlation only measures the strength of relation between two variables where agreement measures compatibility. Agreement is compared by plotting the mean from two GIS estimation methods on the x-axis and the difference between the values in the two methods on the $y$-axis. The data points are measured against the mean difference line, which test bias. Also, the data points are measured against a standard 
deviation of \pm 1.96 . The formula is as follows, where "S1" equals the results from one set of population estimates and "S2" equals the results from one of the other sets being compared:

$$
S(x, y)=\left[\frac{(S 1+S 2)}{2}, S 1-S 2\right]
$$

For an agreement between methods to occur the distribution of points plotted most remain close to the mean difference line and $95 \%$ of points plotted must be within the standard deviation limits. The mean difference line is just the average of all the values being plotted on the y-axis. The closer the points are to this line the more agreement between methods is occurring. Statistical agreement is examined between the centroid containment and areal apportionment, centroid containment and dasymetric mapping, as well as, areal apportionment and dasymetric mapping.

\subsection{Environmental Equity Analysis}

The environmental equity analysis measures inequality by comparing the proportions of at-risk minority populations to the proportion of not-at-risk minority population. It is a measure known as a quotient index. In economics a quotient index that seeks clustering or concentration is referred to as a location quotient (Isserman, A 1977). The quotient index determines if any of the 35 sites demonstrate more minorities at-risk than compared to the minorities in areas considered not-at-risk (Harner, J. 2002). It only assesses whether or not an inequality exists not its severity. The degree of inequality can vary from site to site because the population of a site may have ten people with four being minorities. The severity will not be as high if it's compared to a site with 10,000 people. The populations within the affected areas are summarized for all three GIS techniques inside the half mile buffer to determine which populations are at-risk to which populations are not-at-risk. 
For the environmental equity analysis only the half mile buffer was used as the affected area. A half mile buffer was chosen because it is one of the most frequently chosen distances used in proximity based contamination study (Chakraborty et al. 2011). The Euclidean circular buffer serves as a spatial representation for an approximated contamination zone. Since the true extent of contamination is not known, then the Euclidean distance is the next best approximation. The argument is that the shape of the affected area can be adjusted to match the extent of the pollution for the instances when data is available (Chakraborty et al. 2011), but the Euclidean buffer serves as the next best alternative. In this study the extent of pollution is not known, so the half mile buffer proxy is used across all 35 brownfield sites. The minority population is the accumulation of all non-white categories within the Census data. Whites are considered the majority population in Portland, and this remains a key assertion for this study.

The ratio of at-risk minorities to the total at-risk population was calculated by taking the sum of each GIS technique's population estimate for minorities and dividing that by the total at-risk population. This is calculated for all 35 brownfield sites. The formula is as follows:

$$
\frac{(\text { At }- \text { risk Minorities })}{(\text { Total citywide at }- \text { risk })}=\text { At }- \text { risk Ratio }
$$

Next, the proportion of not-at-risk minorities to the total citywide not-at-risk population is determined. The number of not-at-risk minorities is found by subtracting the total at-risk minority population from the total city-wide minority population. The result is the number of minorities living outside the risk areas. The total of not-at-risk population is found by subtracting the total at-risk population from the entire citywide population. Then, the not-atrisk minority population is divided by the total not-at-risk population. The formula is as follows:

$$
\frac{(\text { Not }- \text { at }- \text { risk Minorities })}{(\text { Total not }- \text { at }- \text { risk citywide population })}=\text { Not }- \text { at }- \text { risk Ratio }
$$


Lastly, the quotient index is created. The quotient index is a proportion of minorities in at-risk areas to their proportions in not-at-risk areas. The formula is as follows:

$\left(\frac{\text { At-risk Minorities } / \text { Total citywide at-risk }=\text { At-risk Ratio }}{\text { Not-at-risk Minorities } / \text { Total not-at-risk citywide population }=\text { Not-at-risk Ratio }}\right)=$ Population Inequity Quotient Index

In this form any value over one or less than one will express that an inequality exists. The minority population is more likely to be at-risk if the value is over one. Any value below one states that the majority (white) population is most at-risk. The following section will describe the results for the three population estimates, the sensitivity analysis, and the environmental equity analysis.

\section{Chapter 4 Results}

\subsection{Centroid Containment Population Estimate}

The population estimate using the centroid containment technique for the entire study area is 583,750 people. The total population in the affected half mile buffer is 88,179 people, which is $15 \%$ of the study areas population. The total number of minorities within the affected area is 27,117 people, which is $5 \%$ of the population. The total number of the majority population within the affected zone is 61,062 people, which is $10 \%$ of the citywide population.

\subsection{Areal Apportionment Population Estimate}

The population estimate using areal apportionment for the entire study area is 583,539 people. The total population in the affected half mile buffer is 88,184 people, which is $15 \%$ of the study areas population. The total number of minorities within the affected area is 26,705 people, which is $4.5 \%$ of the study area population. The total number of the majority population within the affected zone is 61,479 people, which is $10.5 \%$ of the citywide population. 


\subsection{Dasymetric Mapping Population Estimate}

The population estimate using dasymetric mapping for the entire study area is 576,252 people. The total population in the affected half mile buffer is 78,061 people, which is $13.5 \%$ of the study areas population. The total number of minorities within the affected area is 23,159 people, which is $4 \%$ of the citywide population. The total number of the majority population within the affected zone is 54,902 people, which is $9.5 \%$ of the citywide population.

\subsection{Sensitivity Analysis}

The results from the correlation coefficient scatter plots report high levels of correlation. The closer the r-value is to one the higher degree of correlation exists. Figure 3 shows that all three methods have a positive correlation at every distance interval being measured. Although the r-values reported very close to one, variation from the trend line is taking place. For example view Figure 4, which shows the correlation coefficient for the centroid containment population estimate ( $\mathrm{x}$-axis) compared to the dasymetric mapping population estimate (y-axis), has a few outliers.

\begin{tabular}{|r|c|c|c|}
\hline R Values for 0.5 mile & Centroid & Areal Apportionment & Dasymetric \\
\hline Centroid & 1 & 0.997 & 0.992 \\
\hline Areal Apportionment & 0.997 & 1 & 0.995 \\
\hline Dasymetric & 0.992 & 0.995 & 1 \\
\hline R Values for 1 mile & & & Dasymetric \\
\hline Centroid & 1 & Areal Apportionment & 0.995 \\
\hline Areal Apportionment & 0.999 & 0.999 & 0.997 \\
\hline Dasymetric & 0.995 & 0.997 & 1 \\
\hline & & & Dasymetric \\
\hline R Values for 1.5 miles & Centroid & Areal Apportionment & 0.998 \\
\hline Centroid & 1 & 0.99 & 0.998 \\
\hline Areal Apportionment & 0.999 & 1 & 1 \\
\hline Dasymetric & 0.998 & 0.998 & Dasymetric \\
\hline & & & 0.998 \\
\hline R Values for 2 miles & Centroid & Areal Apportionment & 0.998 \\
\hline Centroid & 1 & 0.999 & 1 \\
\hline Areal Apportionment & 0.999 & 1 & Dasymetric \\
\hline Dasymetric & 0.998 & 0.998 & 0.999 \\
\hline R Values for 2.5 miles & Centroid & Areal Apportionment & 0.999 \\
\hline Centroid & 1 & 0.999 & 1 \\
\hline Areal Apportionment & 0.999 & 1 & 0.999 \\
\hline Dasymetric & 0.999 & & \\
\hline & & & \\
\hline
\end{tabular}

Table 1: Correlation Coefficient R-Values for all Distances 


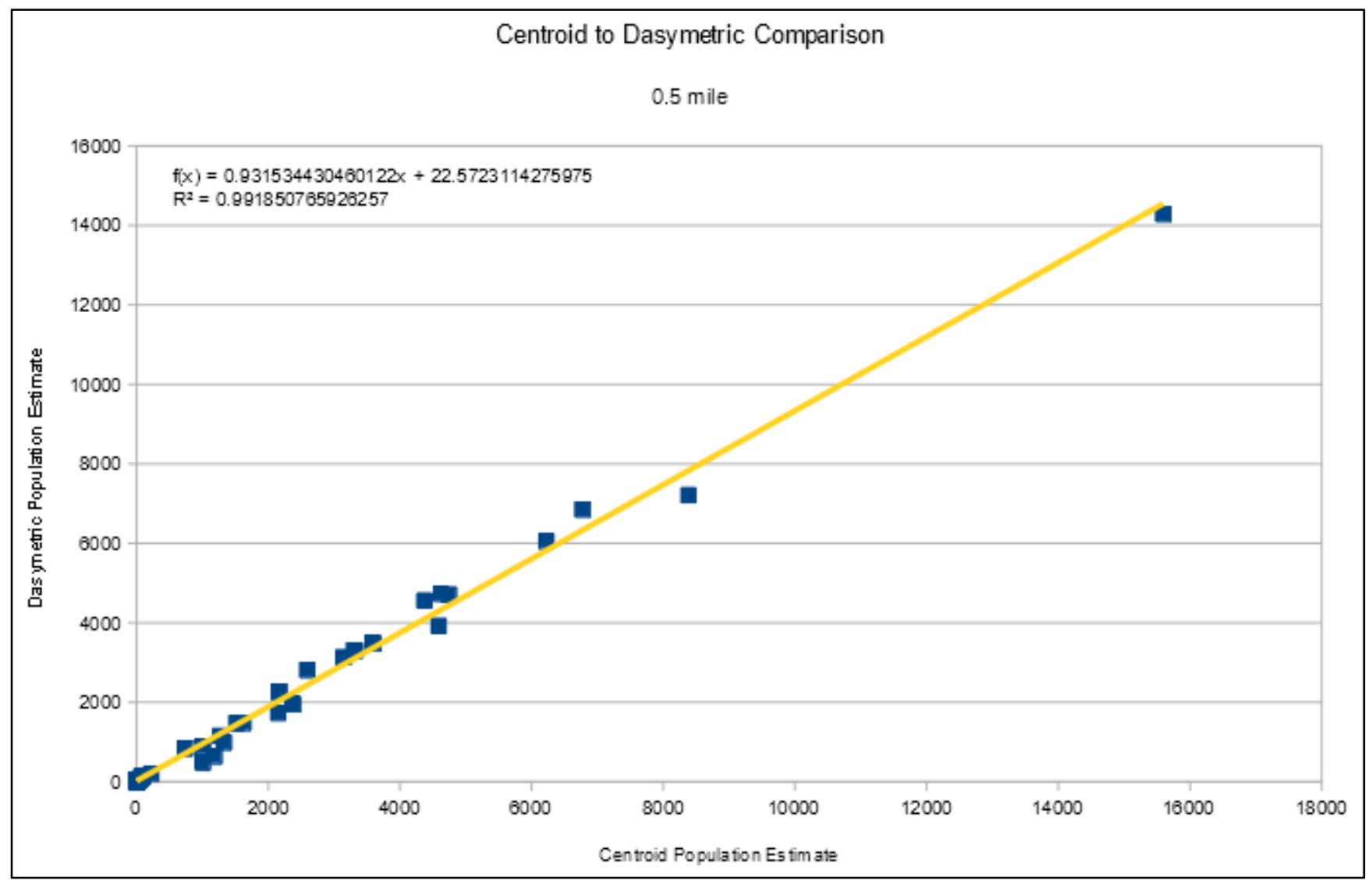

Figure 3: Correlation Coefficient - Trend Line Graph for Centroid Containment to Dasymetric Mapping

The results from the Bland-Altman agreement plot show an acceptable level of agreement for all three methods at all five distances. Each of the 15 plots show $95 \%$ of their data points within the upper and lower limits of agreement (standard deviations). As distances get larger, variation from the mean difference line increased. This is apparent when looking at Figure 5. Also, these results indicate the centroid containment and areal apportionment are the most agreeable, but all methods at the half-mile distance are visibly share the most agreement. 


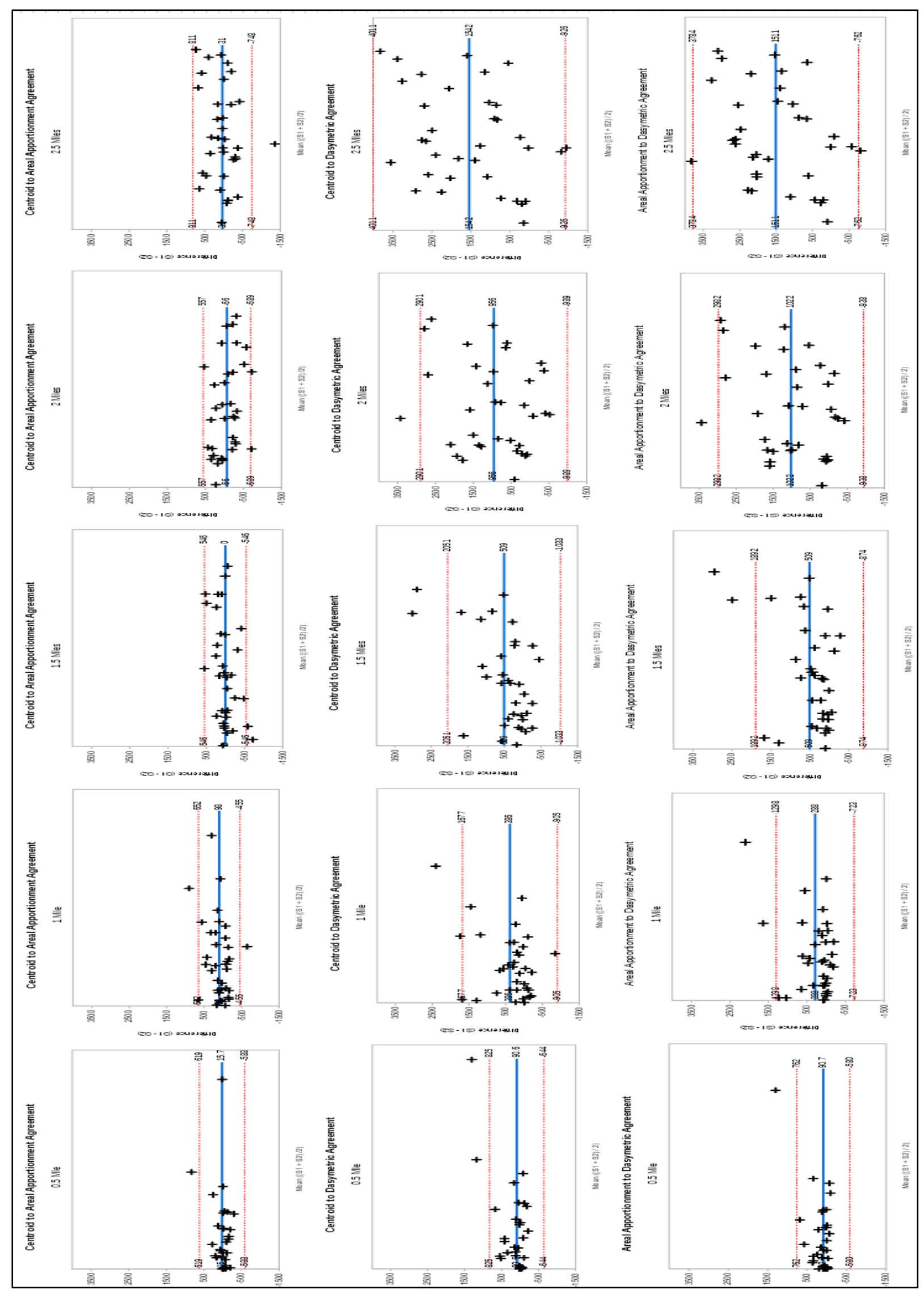

Figure 4: Bland-Altman Statistical Agreement Chart 


\subsection{Environmental Equity Analysis}

The results for the environmental equity analysis are presented by looking at the individual results for all three methods. Each table shows the at-risk percentage and the population inequality quotient index. The overall results are reported first, and then observations are reported by comparing the sets of results. Lastly, site specific results are described.

The first results examined are from the centroid containment method. This is shown in Figure 6. The centroid containment method indicates the most inequity for minorities and the least for the majority. A total of 19 out of 35 sites report that minorities are disproportionately affected compared to the citywide ratio. The second set of results examined are the areal apportionment, has the second most inequity for minorities and second least for the majority. The areal apportionment method has 18 out of 35 sites displaying a disproportionate potential for exposure, as seen in Figure 6. The third set of results observed is from the dasymetric mapping technique. The dasymetric shows the least amount of inequity for the minority population and the most for the majority. This can be viewed in Figure 6 . It has 17 out of 35 sites measuring inequity for minorities. All three sets of results show similar proportions of inequality across all sites with a few exceptions.

Figure 6 also reveals shared anomalies. Interesting results occur in both the centroid containment and the dasymetric mapping techniques. All three methods show site 20 as having the highest level of inequality. They show four sites without minority population or any population, while areal apportionment only shows one site not reporting either population type. All methods show zero minority population or zero total population or a white only population for site 12. Both the centroid containment and dasymetric mapping methods share zero population for sites 3 and 29. The centroid containment method reports a zero 
population for site 32 , and the dasymetric mapping method calculated a zero population for site 19 . The areal apportionment method is the only method to register a minority population in site 3 . Sites 11,14 , and 26 are all in close proximity with regards to their quotient index numbers. They all show the same outcome where the centroid method reports higher proportions of minorities and areal apportionment show lower proportions of minorities, while the dasymetric mapping has quotient index numbers being in the middle of the other two methods.

\begin{tabular}{|c|c|c|c|c|c|c|c|c|}
\hline Site ID\# & \begin{tabular}{|l|l|} 
Centroid \\
\end{tabular} & Centroid quotient index & Site ID\# & Areal Apportionment & AA quotient index & Site ID\# & Dasymetric & Dasymetric quotient index \\
\hline Site 20 & $72 \%$ & 2.66 & Site 20 & $73 \%$ & 2.66 & Site 20 & $71 \%$ & 2.58 \\
\hline Site 25 & $54 \%$ & 1.99 & Site 21 & $54 \%$ & 1.97 & Site 21 & $54 \%$ & 1.98 \\
\hline Site 14 & $50 \%$ & 1.84 & Site 25 & $53 \%$ & 1.95 & Site 25 & $53 \%$ & 1.93 \\
\hline Site 21 & $50 \%$ & 1.83 & Site 29 & $52 \%$ & 1.89 & Site 31 & $46 \%$ & 1.69 \\
\hline Site 31 & $49 \%$ & 1.78 & Site 6 & $48 \%$ & 1.75 & Site 18 & $45 \%$ & 1.65 \\
\hline Site 16 & $48 \%$ & 1.77 & Site 31 & $47 \%$ & 1.72 & Site 1 & $43 \%$ & 1.58 \\
\hline Site 18 & $46 \%$ & 1.71 & Site 16 & $45 \%$ & 1.63 & Site 5 & $43 \%$ & 1.56 \\
\hline Site 5 & $45 \%$ & 1.64 & Site 5 & $44 \%$ & 1.61 & Site 35 & $40 \%$ & 1.47 \\
\hline Site 1 & $42 \%$ & 1.55 & Site 8 & $44 \%$ & 1.60 & Site 14 & $40 \%$ & 1.45 \\
\hline Site 35 & $41 \%$ & 1.51 & \begin{tabular}{|l|} 
Site 18 \\
\end{tabular} & $43 \%$ & 1.57 & Site 34 & $37 \%$ & 1.36 \\
\hline Site 34 & $39 \%$ & 1.45 & Site 1 & $42 \%$ & 1.55 & Site 16 & $36 \%$ & 1.32 \\
\hline Site 33 & $38 \%$ & 1.40 & Site 35 & $39 \%$ & 1.43 & Site 22 & $36 \%$ & 1.31 \\
\hline Site 22 & $35 \%$ & 1.28 & Site 34 & $38 \%$ & 1.39 & Site 33 & $35 \%$ & 1.27 \\
\hline Site 11 & $32 \%$ & 1.17 & Site 33 & $38 \%$ & 1.38 & Site 8 & $34 \%$ & 1.23 \\
\hline Site 26 & $32 \%$ & 1.17 & Site 22 & $36 \%$ & 1.32 & Site 15 & $32 \%$ & 1.15 \\
\hline \begin{tabular}{|l|} 
Site 4 \\
\end{tabular} & $32 \%$ & 1.16 & \begin{tabular}{|l|} 
Site 4 \\
\end{tabular} & $32 \%$ & 1.17 & \begin{tabular}{|l} 
Site 4 \\
\end{tabular} & $30 \%$ & 1.07 \\
\hline Site 15 & $31 \%$ & 1.15 & \begin{tabular}{|l|} 
Site 30 \\
\end{tabular} & $28 \%$ & 1.03 & Site 30 & $28 \%$ & 1.01 \\
\hline Site 8 & $30 \%$ & 1.09 & Site 15 & $28 \%$ & 1.02 & Site 17 & $25 \%$ & 0.90 \\
\hline Site 30 & $28 \%$ & 1.04 & Site 17 & $26 \%$ & 0.94 & Site 9 & $24 \%$ & 0.89 \\
\hline Site 17 & $26 \%$ & 0.95 & Site 27 & $24 \%$ & 0.87 & Site 11 & $24 \%$ & 0.87 \\
\hline Site 9 & $24 \%$ & 0.88 & Site 9 & $24 \%$ & 0.86 & Site 27 & $24 \%$ & 0.87 \\
\hline \begin{tabular}{|l} 
Site 27 \\
\end{tabular} & $24 \%$ & 0.87 & \begin{tabular}{|l} 
Site 2 \\
\end{tabular} & $22 \%$ & 0.80 & \begin{tabular}{|l} 
Site 2 \\
\end{tabular} & $22 \%$ & 0.79 \\
\hline Site 2 & $22 \%$ & 0.81 & Site 28 & $20 \%$ & 0.72 & Site 6 & $21 \%$ & 0.77 \\
\hline Site 6 & $22 \%$ & 0.79 & Site 7 & $20 \%$ & 0.71 & Site 26 & $20 \%$ & 0.74 \\
\hline Site 28 & $20 \%$ & 0.74 & Site 24 & $19 \%$ & 0.71 & Site 28 & $20 \%$ & 0.72 \\
\hline Site 7 & $20 \%$ & 0.73 & Site 11 & $19 \%$ & 0.69 & Site 7 & $19 \%$ & 0.70 \\
\hline Site 24 & $19 \%$ & 0.70 & Site 26 & $18 \%$ & 0.67 & Site 24 & $19 \%$ & 0.70 \\
\hline Site 19 & $14 \%$ & 0.52 & Site 13 & $13 \%$ & 0.49 & Site 13 & $14 \%$ & 0.49 \\
\hline Site 13 & $14 \%$ & 0.50 & Site 10 & $12 \%$ & 0.43 & Site 10 & $12 \%$ & 0.43 \\
\hline Site 23 & $12 \%$ & 0.44 & Site 14 & $11 \%$ & 0.40 & Site 23 & $10 \%$ & 0.38 \\
\hline Site 10 & $12 \%$ & 0.43 & Site 23 & $10 \%$ & 0.37 & Site 32 & $10 \%$ & 0.36 \\
\hline Site 3 & $0 \%$ & 0.00 & Site 19 & $9 \%$ & 0.33 & Site 3 & $0 \%$ & 0.00 \\
\hline Site 12 & $0 \%$ & 0.00 & Site 3 & $7 \%$ & 0.26 & Site 29 & $0 \%$ & 0.00 \\
\hline \begin{tabular}{|l|l} 
Site 29 \\
\end{tabular} & $0 \%$ & 0.00 & \begin{tabular}{|l} 
Site 32 \\
\end{tabular} & $6 \%$ & 0.21 & \begin{tabular}{|l|l} 
Site 19 \\
\end{tabular} & $0 \%$ & 0.00 \\
\hline Site 32 & $0 \%$ & 0.00 & Site 12 & $0 \%$ & 0.00 & Site 12 & $0 \%$ & 0.00 \\
\hline
\end{tabular}

Table 2: Environmental Equity Analysis Results for All Three Methods

Finally, the results in Figure 6 display individual discrepancies between each method.

The areal apportionment method is calculating a much higher proportion minority population for site 6 . This site shows a quotient index of 1.7 , while the other methods show 0.8 . The dasymetric mapping method has unique indices for both sites 19 and 32. Site 32 reports as more inequality when compared to the other two methods. The dasymetric mapping 
technique has much higher indices for minorities. It reports a quotient index of 0.35 while the other sites register as much less or not at all. Site 19 does not count a minority population, whereas the other two methods do find a minority population. An explanation of these results will be discussed in the preceding chapter.

\section{Chapter 5 Discussion}

\subsection{GIS Population Estimates}

For this section the results from the three GIS population estimates are discussed as a comparison rather than each result individually. The US Census reported that Portland, Oregon's population for 2010 was 585,261(US Census 2013). All three methods calculated less people within the city limits than the Census. Both the centroid containment and areal apportionment expressed a less than $0.03 \%$ difference in population. The reason for this discrepancy is unknown, but it is likely that the study area data for the city limits or Portland was slightly different in this study then that of the US Census. Regardless, the statistical difference is minima.

A large difference between the total population estimated in the dasymetric mapping method and the population reported by the Census is evident. The dasymetric method estimated a population with $2.5 \%$ less people in it. This ended up being a significant difference, which resulted in about 9,000 people not being estimated. Initially, it appeared to be an error in the calculation, but after verifying the results with the source census blocks, an issue with the data became apparent. The cause of the population difference was the result of the ancillary buildings data not having exact classification for single-family residential or multifamily residential buildings across the entire dataset. Remember, the population for dasymetric mapping is relative to the building volume within each census block. If a census block contains a small amount of residential buildings by volume, then the population will be 
an example of how this occurs can be seen below when results from the environmental equity analysis for site 3 is examined.

Overall, the three GIS methods had less than $1 \%$ difference when comparing the percentage of populations within the affected area. This held true regardless of looking at minority populations or the majority population. As stated above, the only major discrepancy was the difference in total population count for dasymetric mapping. Keeping that in mind the analysis continued forward.

\subsection{Sensitivity Analysis}

Typically, a correlation coefficient is a sufficient measurement for comparison when conducting spatial analysis. However, the results for these three GIS population estimates the correlation was so high that it was unclear if a difference between methods was taking place. Since all three methods relied on the same source data, the census blocks, a high correlation was expected, but not to the extent reported in the results. Each method redistributed the data into to different spatial units, so some degree of variation should have occurred. A closer examination of the scatter plots at a half-mile distance showed that small amounts of variation were occurring. In particular the variation was most obvious between the dasymetric mapping and the centroid containment method (See Figure 4). The minor variation from the trend provoked the need to examine statistical agreement.

The Bland-Altman statistical agreement measurement provided a significantly different perspective between the three methods. It was immediately obvious that all three methods corresponded at the half-mile distance. It is easily verified by comparing the limits of agreement (standard deviations) for the plots with larger and larger distances (See Figure 5). These observations aligned with previous research discussed in the methods section, but 
more importantly it solidified the choice of the half-mile buffer distance for the environmental equity analysis.

Another unique insight drawn from the statistical agreement plots is how closely the centroid containment and areal apportionment agree with each other regardless of distance. The compatibility between these two methods mean that they can be used interchangeably across all five distances chosen for this study, however, variation does begin to occur at the two and a half mile interval. Testing at larger distances needs to take place before methods can be interchanged at distance beyond two and half miles.

The dasymetric mapping technique presented the least amount of agreement. While the half-mile distance didn't show a huge amount of variation, the lack of agreement between both the centroid containment method and areal apportionment method became noticeable at the mile and a half distance. The upper and lower limits of agreement (standard deviations) had wider and wider ranges with each distance interval. Agreement at the half-mile distances seems to happen because the dasymetric mapping uses buildings that are not contiguous features. These units are reliant on building volume to account for population density instead of area. Since the area of the census blocks within a half-mile are closer in size to the buildings data, then it means they will be more agreeable. Also, in areas with higher density single-family residential (SFR) and multi-family residential (MFR) the dasymetric mapping technique can easily place the population into these spatial units, but for areas with low SFR or MFR buildings the dasymetric technique doesn't have anywhere to distribute the population. The larger the distance then the more likely this is to occur.

\subsection{Environmental Equity Analysis}

Overall the results for the environmental equity analysis showed minimal differences between all three methods. At a half-mile buffer distance this result means any of the three 
population estimation techniques can be used. The ease of each estimation process may be a larger factor than the quantitative results, but there are a few key differences worth being discussed.

The centroid method had the most variation in its results between the three methods. Also, it registered the most sites with inequities for the minority population then the other two techniques (See Figure 6 and 7). These results mean that this method can either over estimate the population or under estimate the population depending on where the shape of the census block. The shape of a census block determines where the centroid will fall and thusly whether or not it ends up within the half-mile buffer. The population inequality quotient index for sites 19 and 32 are good examples of the centroid containment method over estimating and under estimating respectively.

\begin{tabular}{|r|r|r|r|}
\hline & Centroid Containment & Areal Apportionment & Dasymetric Mapping \\
\hline Sum & 37.54 & 38.12 & 35.20 \\
\hline Average & 1.07 & 1.09 & 1.01 \\
\hline Variation & 0.40 & 0.38 & 0.37 \\
\hline
\end{tabular}

Table 3: Environmental Equity Analysis Results Key Statistics

The areal apportionment method tends to estimate higher than the other two methods based on the sum and average of the population inequality quotient index results (See Figure 7). The contiguous spatial representation from this method is the cause of this result. The areal apportionment method is over estimating the population because it is accounting for people living in a space where they do not exist. Sites 6 and 29 is a good example where this is the case (See Figure 8). The apportioned census blocks are estimating populations on natural areas. 


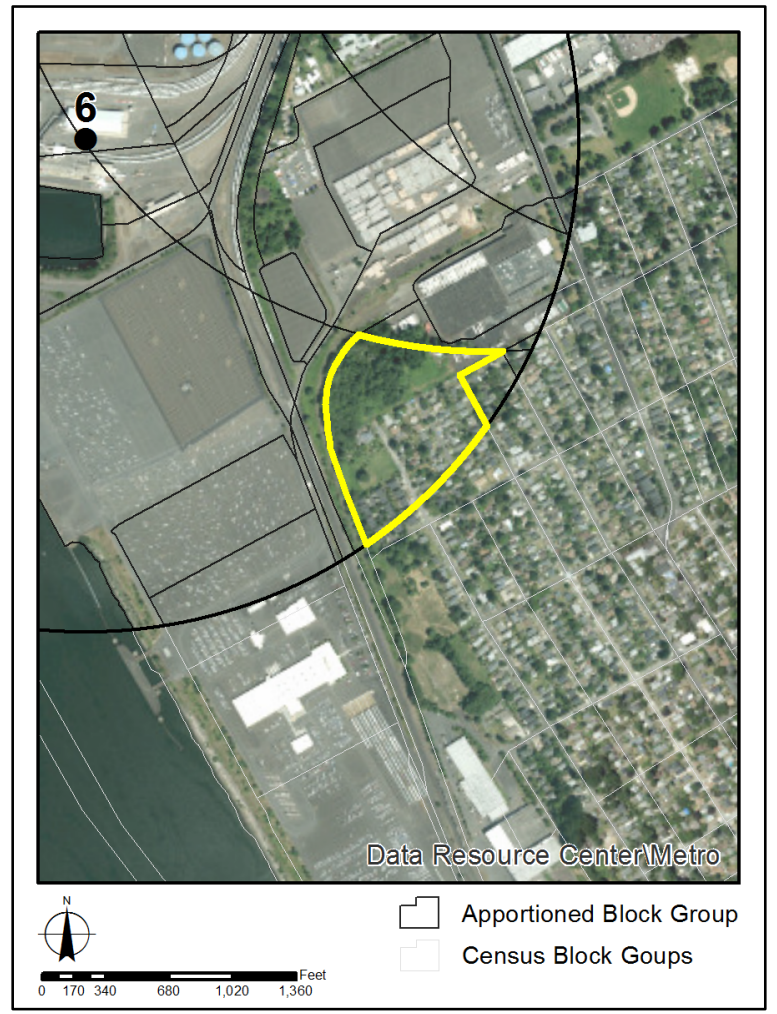

Figure 5: Map of Site \#29

The dasymetric mapping method estimated the least amount of inequality for minorities and the least amount of variation (See Figure 7). These reason for these results is likely due to the calculations using building volume. Since the spatial units of buildings are not contiguous, then the populations from the two-dimensional census blocks are being redistributed into three-dimensional space. This is opposed to the other two methods where the populations are being reorganized into small two-dimensional spatial units. Site 32 is a great example where this occurs (See Figure 9). 


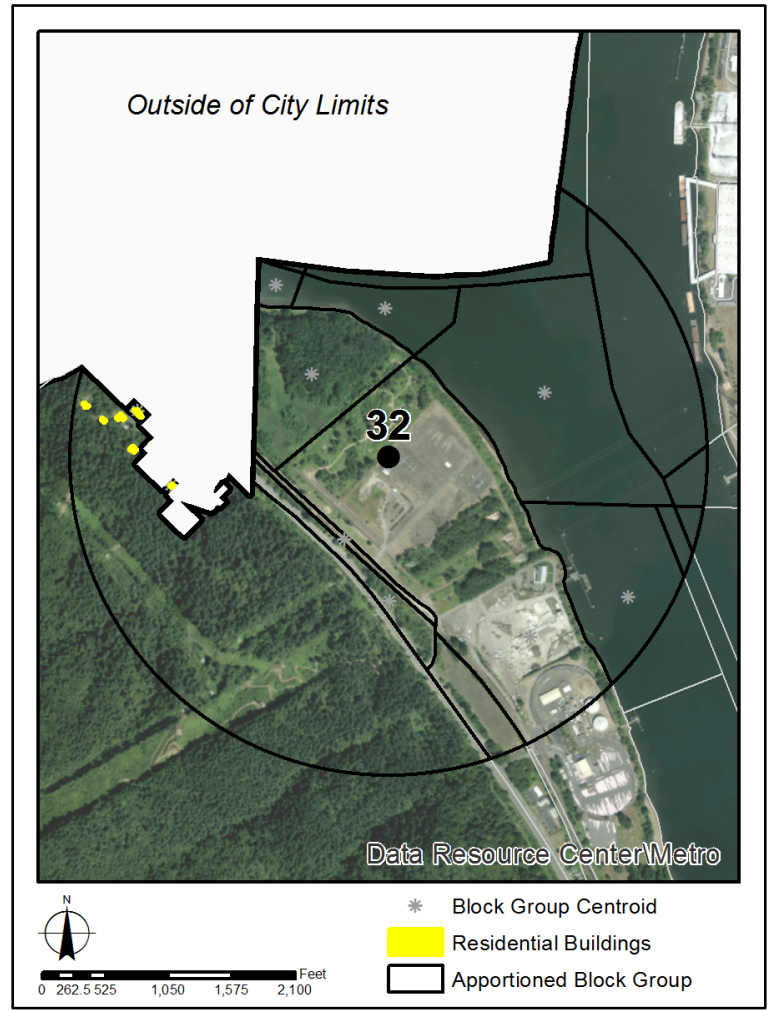

Figure 6: Map of Site \#32

Aside from the results specific to each individual method, some other interesting outcomes are worth noting. Both centroid containment and dasymetric mapping show four sites without minority population or any population, while areal apportionment only shows one site without a minority population or any population. Site 3 is a sufficient example (See Figure 10). 


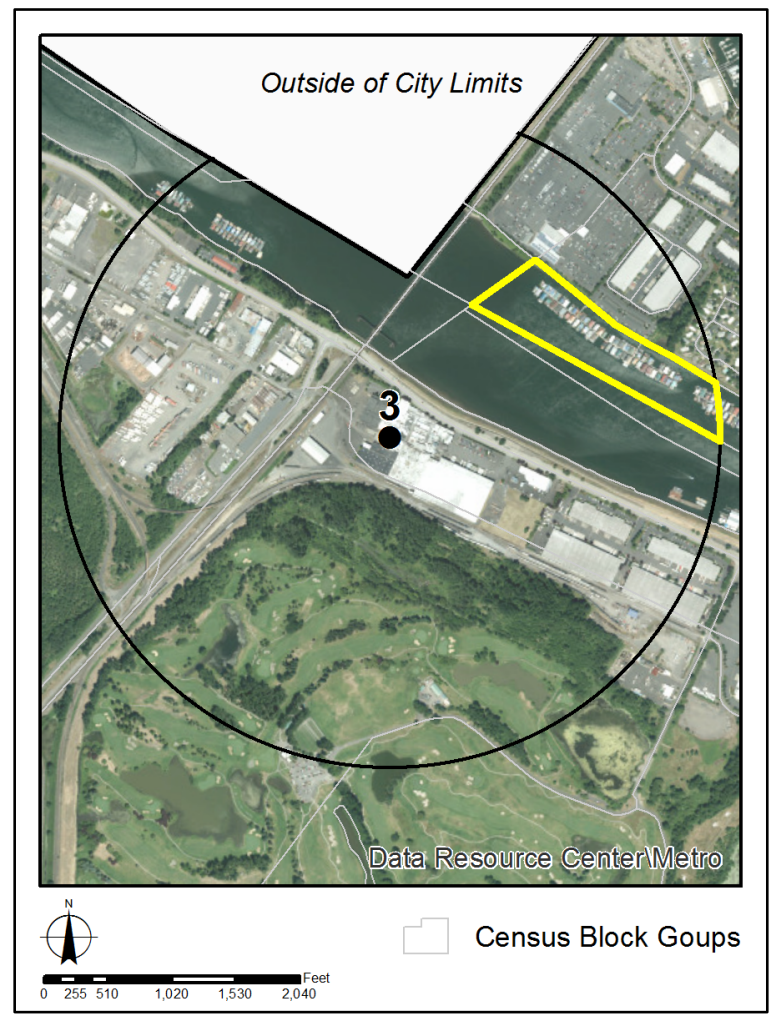

Figure 7: Map of Site \#3

It shows an issue with census block shape and the buildings data used in the dasymetric mapping technique. The aerial photo for this area shows houseboats on the river. These aren't accounted for in the buildings data. Also, the census blocks have a peculiar shape due to the underlying geographic feature, the water. The conclusion is that the brownfield sites in this study that are near the periphery of the study area are going to have more variation in the results.

Another site worth noting is number 19 , because all of the methods posted no minority population and quite possibly no population at all. An examination of the census blocks and areal photography showed that this area was highly industrial and in between two large natural areas, Overlook Park and the Willamette River. It is easy to conclude that the residential is nearly nonexistent for this site. Both Centroid containment and areal apportionment count a population being near this site while dasymetric does not. This is 
caused by a lack of SFR and MFR buildings within the half-mile buffer (See Figure 11). Again, it highlights shortfall in using the dasymetric mapping technique. The accuracy of data will always play a key component in the results.

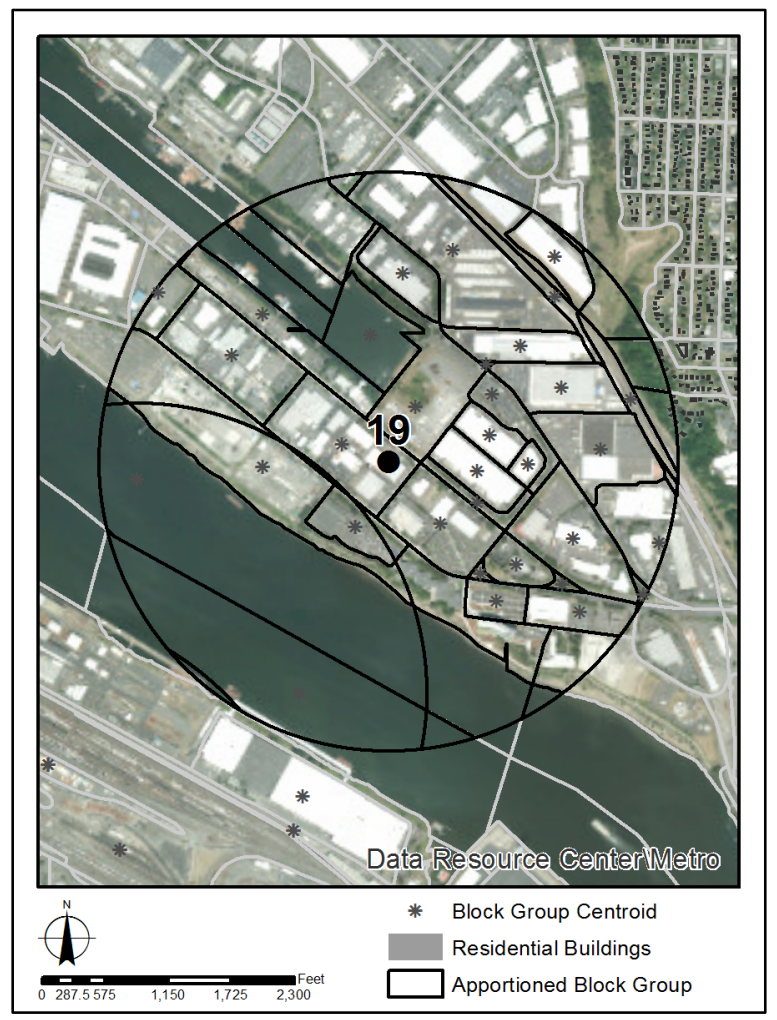

Figure 8: Map of Site

Lastly, site 20 showed the highest amount of minority populations living within the extent of potential risk. All three sites agreed and showed approximately the same percentages and quotient indices. Previously, in this paper it was suggested that these techniques can be used to target specific areas where minority groups may be vulnerable to contamination. Site 20 would be brownfield worth investigating further. Ultimately, there are plenty more sites worth investigating but the level of inequality showed in the population inequality quotient index and the agreement between all three methods indicates it is a high priority site. 


\section{Chapter 6 Challenges and limitations}

There are many challenges and limitations surrounding GIS for use in environmental justice research. I will discuss three. One such challenge is determining the type of dasymetric mapping to use when comparing to the other population estimation techniques. The reason is a lack of standardization for dasymetric mapping (Eicher and Brewer 2001). The second, which is a limitation, is the inclusion of other key drivers of inequality, such as economic class, age, or education. The inclusion of more drivers of inequality may support the environmental equity analysis overall, but it doesn't add or take away from the comparison of estimation techniques (Brulle and Pellow 2006). The third challenge and limitation is the consideration of affordable housing and its effect on areas where higher economic prosperity are observed. Affordable housing is seen as a challenge because measuring its affects at each site adds complexity to the overall project. Also, it is a limitation because it is known quantity within the city of Portland and it may be having some positive affect on environmental justice (Fenelon 2017).

All three of these challenges and limitations are discussed by various journals (Chakraborty et al. 2011; Sheppard et al. 1999; Sridharan and Qiu 2013; Mennis 2002) for the research conducted in this project. The challenge of utilizing different forms of dasymetric mapping was resolved in this paper by keeping the three GIS methods in the same data format. While that doesn't answer whether a raster based dasymetric method has comparable results to the areal apportionment or centroid containment methods, it did keep continuity between population estimation methods and could be answered with a similar study. An expansion of the scope of this project can be completed to address the limitation of using only minority populations as an inequality indicator; however, according to the research mentioned above focusing on one key indicator was deemed effective. Affordable housing and its overall 
effect on neighborhoods appears to be an emerging area of study. Future research can provide answer for understanding the effects affordable housing might have on reducing inequality in areas where it previously may have been less prevalent.

\section{Chapter 7 Conclusion}

This paper serves as descriptive comparison between three similar forms of demographic areal interpolation for estimating populations. All three forms of analysis seek to count and summarize the number of people within a buffered half-mile distance from a know environmental contaminate. The goal was to examine the overall effect each method may have on an environmental equity analysis.

While the results of this comparison showed minimal quantitative difference across all three techniques, the vector based dasymetric method showed a trend in reducing the variation of people being counted. This was a part the anticipated trend, but it was believed that it would result in more inequity being displayed. An issue in the results elucidated incomplete or inaccurate buildings data. It is problematic to have control units with ambiguous reliability, but it will be an issue that is resolved over time as the data reporting and creation becomes better. In the mean time any future examination should seek to resolve the issue of classification by identifying ways to correct the buildings data. Also, the results showed that the centroid method can over estimate and under estimate populations, which can make it less reliable. The areal apportionment method tended to over estimate when comparing it to centroid containment and dasymetric mapping. In conclusion the results do not indicate if either method is better than the other, but it is fair to say that each method proves more powerful depending on the size of the exposure area. 


\section{References:}

Arvai, J. and Gregory, R. 2003. Testing Alternative Approaches for Identifying Cleanup Priorities at Contamination Sites. Environmental Science and Technology 37(8): 14691476.

Bland, J.M. and Altman, D.G. 1983. Measurements in Medicine: the Analysis Comparison Studies. The Statisticians 32: 307-317.

Bowen, W. and Wells, M. 2002. The Politics and Reality of Environmental Justice: A History and Considerations for Public Administrators and Policy Makers. Public Administration Review 62(6): 688-698.

Brulle, R. and Pellow, D. 2006. Environmental Justice: Human Health and Environmental Inequalities. Annual Review of Public Health 27: 103-124.

Chakraborty, J. et al. 2011. Disproportionate Proximity to Environmental Health Hazards: Methods, Models, and Measurement. American Journal of Public Health 101(Supplement 1): S27-S36.

De Sousa, C. 2003. Turning Brownfields into Green Space in the City of Toronto. Landscape and Urban Planning 62: 181-198.

Dillon, L. 2014. Race, Waste, and Space: Brownfield Redevelopment and Environmental Justice at Hunters Point Shipyard. Antipode 46(5): 1205-1221.

Eicher, C. and Brewer, C. 2001. Dasymetric Mapping and Areal Interpolation: Implementation and Evaluation. Cartography and Geographic Information Science 28(2): 125-138. 
Elliot, J. and S. Frickel. 2011. Environmental Dimensions of Urban Change: Uncovering Relict Industrial Waste Sites and Subsequent Land Use Conversions in Portland and New Orleans. Journal of Urban Affairs 33(1): 61-82.

Ghanbari, A. and Ghanbari, M. 2013. Assessing Spatial Distribution of Tabriz Parks by GIS (Compared Network Analysis and Buffering). Geography and Environmental Planning Journal 50(2): 57-60.

Harner, J. et al. 2002. Urban Environmental Indices. The Professional Geographer 54(3): 318-331.

Harvey, T. and M. Works. 2002. Urban Sprawl and Rural Landscapes: Perception of Landscape as Amenity in Portland, Oregon. Local Environment 7(4): 381-396.

Isserman, A. 1977. The Location Quotient Approach to Estimating Regional Economic Impacts. Journal of American Institute of Planners 43(1): 33-41.

Lambin, E. et al. 2001. The Causes of Land-use and Land-cover Change: Moving Beyond Myths. Global Environment Change 11(4): 261-269.

Maantay, J. et al. 2008. Research Note - A New Method for Mapping Population and Understanding the Spatial Dynamics of Disease in Urban Areas: Asthma in the Bronx, New York. Urban Geography 29(7): 724-738.

Mah, A. 2017. Environmental Justice in the Age of Big Data: Challenging Toxic blind Spots of Voice, Speed, and Expertise. Environmental Sociology 3(2): 122-133.

Masters, G. 2008. Chapter 4: Risk Assessment. In Introduction to Environmental Engineering and Science $3^{\text {rd }}$ ed. 117-156. Upper Saddle River, NJ: Prentice Hall. 
Mennis, J. 2002. Using Geographic Information Systems to Create and Analyze Statistical Surfaces of Population and Risk for Environmental Justice Analysis. Social Science Quarterly 83(1): 282-297.

Schadler, S. et al. 2010. Designing Sustainable and Economically Attractive Brownfield Revitalization Options Using an Integrated Assessment Model. Journal of Environmental Management 92(1): 827-937.

Sheppard, E. et al. 1999. GIS-based measures of environmental equity: Exploring their sensitivity and significance. Journal of Exposure Analysis and Environmental Epidemiology 9(1): 18-28.

Sridharan, H. and Qui, F. 2013. A Spatially Disaggregated Areal Interpolation Model Using Light Detection and Ranging-Derived Building Volumes. Geographical Analysis 45(1): 238-258.

The State of Oregon. 2016. Environmental cleanup Site Information Database - Frequently Asked Questions. Department of Environmental Quality. http://www.oregon.gov/deq/Hazards-and-Cleanup/env-cleanup/Pages/ecsi.aspx

Thomas, M. 2002. A GIS-Based Decision Support System for Brownfield Redevelopment. Landscape and Urban Planning 58: 7-23.

US Census. 2013. American Fact Finder. Factfinder.census.gov

World Commission on Environment and Development. Our Common Future—Brundtland Commission; Oxford University Press: Oxford, UK, 1987.

Zandbergen, P. and Chakraborty, J. 2006. Improving Environmental Exposure Analysis Using Cumulative Distribution Functions and Individual Geocoding. International Journal of 
Health Geographics 5(23). Available at https://www.ncbi.nlm.nih.gov/pmc/articles/PMC1523259/ (last accessed 01 December 2016). 